\title{
Myoglobinuria: the importance of reaching a firm diagnosis - a patient with defective fatty acid oxidation
}

\author{
C.J. Ellis ${ }^{1}$, A.G. Dewhurst ${ }^{1}$, M. Cooper ${ }^{2}$, D.P. Brenton ${ }^{2}$ and J.R.E. Dathan ${ }^{1}$ \\ ${ }^{1}$ Department of Medicine, Royal South Hants Hospital, Lyon Street, Southampton and ${ }^{2}$ Department of \\ Medicine, University College and Middlesex School of Medicine, University Street, London, UK.
}

\begin{abstract}
Summary: A 52 year old man presented with myoglobinuria-induced acute renal failure requiring dialysis. Despite renal biopsy, the cause of the myoglobinuria was not established until he re-presented a year later with a milder episode. At this stage investigations, including a muscle biopsy, demonstrated a defect in fatty acid oxidation amenable to dietary and lifestyle advice. This report emphasizes the importance of reaching a definitive diagnosis in myoglobinuria.
\end{abstract}

\section{Introduction}

We report a patient with a rare muscle disorder (defective fatty acid oxidation) who presented with two episodes of myoglobinuria-induced acute renal failure before the correct diagnosis was made. This condition requires dietary treatment and this report highlights the importance of making an accurate diagnosis in such a patient.

\section{Case report}

A previously well 52 year old engineer presented following a 10-day history of myalgia, vomiting and 'chocolate-coloured' urine. Examination was normal. Mid-stream urine revealed no casts, infection or visible myoglobin, renal ultrasound was normal, urea $52 \mathrm{mmol} / \mathrm{l}(3.0-6.5 \mathrm{mmol} / \mathrm{l})$, creatinine $1224 \mu \mathrm{mol} / 1(60-125 \mu \mathrm{mol} / \mathrm{l})$, aspartate transaminase $>450 \mathrm{IU} / 1(5-42 \mathrm{IU} / \mathrm{l}$, potassium $5.5 \mathrm{mmol} / \mathrm{l}(3.5-5.0 \mathrm{mmol} / \mathrm{l})$. Two days later the aspartate transaminase had fallen to $103 \mathrm{IU} / 1$ when the creatine kinase was $4880 \mathrm{IU} / 1(25-195 \mathrm{IU} / \mathrm{l})$, suggesting a higher peak value of creatine kinase before admission. Peritoneal dialysis followed by haemodialysis was required before the acute renal failure resolved. Renal biopsy showed marked tubular damage and a moderate interstitial infiltrate, with immuno-peroxidase evidence of tubules containing red-brown material, compatible with myoglobin.

The patient remained well and the following year he obtained a postman's job in his rural area, which involved 5 miles of walking and cycling daily.

Correspondence: A.G. Dewhurst, M.R.C.P. Accepted: 21 July 1989.
After 2 days, he was re-admitted with leg muscle cramps and red-brown urine. Investigations revealed visible myoglobinuria (laboratory confirmed), urea $8.8 \mathrm{mmol} / \mathrm{l}$, creatinine $138 \mu \mathrm{mol} / \mathrm{l}$, potassium $3.8 \mathrm{mmol} / \mathrm{l}$, aspartate transaminase $>300 \mathrm{IU} / \mathrm{l}$, creatinine kinase $>36000 \mathrm{IU} / \mathrm{l}$. With bed rest, the symptoms and biochemistry returned to normal.

Further history at this stage indicated several episodes during his life of exercise-induced severe muscle cramps, including one as a young army recruit when he had to drop out of an exercise march. Having excluded other commoner causes of myoglobinuria (see discussion), a muscle enzyme defect was suspected. An ischaemic forearm test showed a normal rise of lactate after anaerobic exercise - lactate levels: pre-test 1.3 $\mathrm{mmol} / 1(0.6-2.4 \mathrm{mmol} / \mathrm{l})$, immediately post-test $8.0 \mathrm{mmol} / 1,20$ minutes post-test $2.0 \mathrm{mmol} / 1$ - and a provisional diagnosis of a defect in fatty acid oxidation was made. Muscle biopsy was performed 6 months later (when the muscle would have regained its normal histology) and confirmed this diagnosis.

\section{Methods and results}

Mitochondria isolated from a quadriceps muscle tissue obtained by needle biopsy demonstrated a decreased oxidation of palmityl carnitine, $0.02 \mu \mathrm{mol} \mathrm{min}^{-1}$. g. tissue ${ }^{-1}$ (normal $0.73+0.17$ s.e.m., $n=9$ ). Oxidation of pyruvate and the activity of succinate cytochrome reductase and cytochrome oxidase were all normal in the same biopsy. ${ }^{1}$

The accumulation in the muscle of short chain fatty acid carnitine esters $15.3 \mu \mathrm{mol}, \mathrm{g}$ protein $^{-1}$ (normal $0.8-4.0$ ) and of long chain fatty and 
carnitine esters $1.17 \mu \mathrm{mol}, \mathrm{g}$ protein ${ }^{-1}$ (normal $0.1-0.7$ ) is consistent with the restricted metabolism of these fatty acid intermediates. This could arise from a deficiency of carnitine palmityl transferase (CPT) or in beta-oxidation (see below). Organic acid investigations on both urine and plasma were normal without any abnormal dicarboxylic acids.

He was advised to have a low fat diet and to follow a more sedentary life-style, both treatments reported to prevent further rhabdomyolysis in this condition, ${ }^{2}$ and he remains well a year later.

\section{Discussion}

Rhabdomyolysis is the syndrome resulting from skeletal muscle injury, with the release of muscle cell contents into plasma. These include enzymes of which creatine kinase is the most sensitive indicator of rhabdomyolysis ${ }^{3}$ and myoglobin. Myoglobinuria occurs at the low serum concentration of $1.5 \mathrm{mg} / \mathrm{dl}$. However, the distinctive brown colouration only becomes visible to the naked eye once the myoglobin concentration exceeds $100 \mathrm{mg} / \mathrm{dl}$. There are many causes of myoglobinuria: toxins (especially alcohol), infections, drugs, muscle trauma (including epilepsy), metabolic disorders and immunological diseases (e.g. polymyositis) being among the more common. ${ }^{4}$ Exercise-induced myoglobinuria may result from defective glycogen utilization with enzyme abnormalities such as myophosphorylase deficiency (McArdle's disease) or muscle phospho-fructokinase deficiency (Tauri's disease) in the carbohydrate pathway. Similarly, deficiencies in lipid metabolism may cause an energy (adenosine triphosphate: ATP) deficit resulting in muscle breakdown. ${ }^{5}$

Depending upon the metabolic state, skeletal muscle uses variable proportions of glucose or free fatty acids and ketone bodies as fuel. Integrity of both the lipid and carbohydrate metabolic pathways is therefore essential for normal muscle function. Normally more than $50 \%$ of the energy requirement of resting skeletal muscle is supplied from the oxidation of lipids, but this quantity increases during fasting when glucose is spared. During short bursts of strenous activity skeletal muscle predominantly uses muscle glycogen. ${ }^{6}$

Figure 1 demonstrates these enzyme defects in the pathways of lipid and carbohydrate metabolism. A simple test to distinguish between defects in the 2 pathways is the 'ischaemic forearm test' but it carries some risk of contracture formation in defects of carbohydrate metabolism. In this the forearm is cuffed at above systolic blood pressure, and a vigorous hand-squeezing exercise is performed. Venous samples show a normal rise of lactate after anaerobic exercise with the lipid

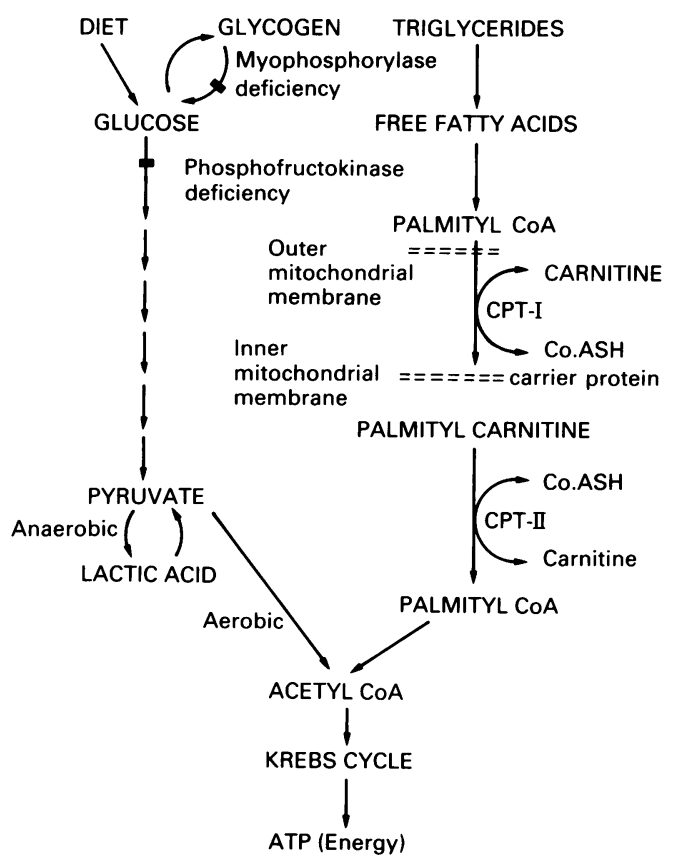

Figure 1 Lipid and carbohydrate metabolism pathways in skeletal muscle: sites of potential enzyme defects.

pathway defects (as in our patient), but not with an enzyme deficiency in glycogenolysis. ${ }^{7}$ There are 2 distinct currently recognizable deficiencies concerned with the transfer of fatty acids into mitochondria. In myopathic carnitine deficiency, only the skeletal muscle tissues contain low concentrations of L-carnitine. The clinical symptoms in this condition are those of muscle weakness, and muscle biopsy shows a gross lipid storage myopathy.

Two carnitine palmityl transferase (CPT) enzymes have been recognized; CPT-I located on the inner face of the outer mitochondrial membrane and CPT-II located on the inner face of the inner mitochondrial membrane. Carnitine palmityl transferase deficiency can cause exercise-induced muscle cramps and myoglobinuria, ${ }^{8}$ worsened by fasting, cold or high fat diet; myopathy is not usually a feature. ${ }^{9}$

Carnitine palmityl transferase deficiency was first reported by Di Mauro and Bank and colleagues $^{10,11}$ who found 2 brothers with the condition. Cases previously described as 'paroxysmal myoglobinuria' or the 'Meyer-Betz syndrome' were probably also due to carnitine palmityl transferase deficiency. ${ }^{12}$ The genetic basis of inheritance is unclear, and although autosomal recessive with differing expression is likely, sub-groups do seem to exist. ${ }^{13.14}$ Fewer examples of genetic defects in the beta-oxidation pathway have been described.

It is likely that the patient reported here is 
CPT-II deficient but further investigations would be required to establish whether the defect in this patient is in the CPT-II enzyme or in the betaoxidation of long chain fatty acids. More accurate diagnosis would not alter treatment but this report emphasizes the need to make an accurate diagnosis in any patient with myoglobinuria, at least as far as

\section{References}

1. Gohil, K., Jones, D.A. \& Edwards, R.H.T. Fatty acid oxidation in mitochondria from needle biopsy samples of human skeletal muscle. Clin Sci 1984, 66: 173-178.

2. Trevisan, C.P., Grazia, I. \& Angelini, C. Exercised-induced recurrent myoglobinuria: defective activity of inner carnitine palmityl transferase in muscle mitochondria of two patients. Neurology 1987, 37: 1184-1188.

3. Hess, J.W., MacDonald, R.P., Frederick, R.J. et al. Serum creatine phosphokinase (CKP) activity in disorders of heart and skeletal muscle. Ann Intern Med 1964, 61: 1015-1028.

4. Gabow, A.P., Kaehny, W.D. \& Kelleher, S.P. The spectrum of rhabdomyolysis. Medicine 1982, 61: 141-152.

5. Pleasure, D. \& Bonilla, E. Skeletal muscle storage diseases: myopathies resulting from errors in carbohydrate and fatty acid metabolism. In: Mastalgia, Fl. \& Walton, J. (eds) Skeletal Muscle Pathology, vol. 10. Churchill Livingstone, Edinburgh, London 1982, pp. 340-359.

6. Havel, R.J. Caloric homeostasis and disorders of fuel transport. N Engl J Med 1972, 287: 1186-1192.

7. Reza, M.J., Kar, N.C., Pearson, C.M. et al. Recurrent myoglobinuria due to muscle carnitine palmityl transferase deficiency. Ann Intern Med 1978, 88: 610-615.

8. Bertorini, T., Yeh, Y., Trevisan, C. et al. Carnitine palmityl transferase deficiency. Myoglobinuria and respiratory failure. Neurology 1980, 30: 263-271. determining whether there is a defect in oxidation of carbohydrates and fatty acids. Such metabolic defects render the patient at risk of recurrent myoglobinuria and repeated episodes of acute renal failure, yet may respond well to appropriate preventive therapy.

9. Cumming, W.J.K., Hardy, M., Hudgson, P. et al. Carnitine palmityl transferase deficiency. J Neurol Sci 1976, 30: 247-258.

10. DiMauro, S. \& DiMauro, P.M.M. Muscle carnitine palmityltransferase deficiency and myoglobinuria. Science 1973, 182: 929-931.

11. Bank, W.J., DiMauro, S., Bonila, E. et al. A disorder of muscle lipid metabolism and myoglobinuria - absence of carnitine palmityltransferase. $N$ Engl J Med 1975, 292: 443-449.

12. Hosteller, K.Y., Hoppel, C.L., Romine, J.S. et al. Partial deficiency of muscle carnitine palmityltransferase with normal ketone production. $N$ Engl J Med 1978, 298: 553-557.

13. Ionasescu, V., Hug, G. \& Hoppel, C. Combined partial deficiency of muscle carnitine palmityltransferase and carnitine with autosomal dominant inheritance. $J$ Neurol Neurosurg Psychiatry 1980, 43: 679-682.

14. Angelina, C., Freddo, L. \& Battistella, P. Carnitine palmityl transferase deficiency: clinical variability, carrier detection, and autosomal-recessive inheritance. Neurology 1981, 31: 883-886. 